\title{
EMPRESARIAMENTO DA EDUCAÇÃO DE NOVO TIPO: MERCANTILIZAÇÃO, MERCADORIZAÇÃO E SUBSUNÇÃO DA EDUCAÇÃO AO EMPRESARIADO'
}

\author{
Vânia Cardoso da $\operatorname{Motta}^{2}$ (UFRJ) \\ Maria Carolina Pires de Andrade ${ }^{3}$ (UFRJ)
}

\begin{abstract}
Resumo
O artigo versa sobre o empresariamento da educação de novo tipo, em vista do progressivo protagonismo assumido por frações empresariais na educação brasileira nos últimos trinta anos. Tal protagonismo robustece a trincheira de poder junto ao Estado ampliado por meio dos aparelhos privados de hegemonia e opera a supremacia burguesa no âmbito da educação. Considerando a irrompível organicidade entre estrutura e superestrutura e as particularidades da formação econômico-social brasileira, definimos duas dimensões centrais desse processo, quais sejam a capitalização da/na educação (cujos aspectos principais são a mercantilização e a mercadorização) e a subsunção da educação ao empresariado. Apontamos implicações desse processo para a educação brasileira, como o aumento da precarização e da expropriação do processo formativo, discutindo suas funcionalidades no âmbito da reprodução ampliada do capital.
\end{abstract}

Palavras-chave: Empresariamento da educação de novo tipo; Capitalização da educação; Subsunção da educação ao empresariado; Capitalismo dependente.

\begin{abstract}
The article deals the empresariamento da educação de novo tipo, protagonized show by business fractions in brazilian education in the last thirty years. This protagonism strengthens the trench of power with the enlarged state through the private apparatus of hegemony and operates the bourgeois supremacy in the
\end{abstract}

\footnotetext{
${ }^{1}$ Este artigo é uma nova versão da comunicação no evento Marx e Marxismo: Marxismo sem tabus -Enfrentando Opressões - 2019, organizado pelo Núcleo Interdisciplinar de Estudos e Pesquisas em Marx e Marxismo (NIEP), Universidade Federal Fluminense.

2 Doutora em Serviço Social pela Universidade Federal do Rio de Janeiro (UFRJ). Docente na mesma universidade. e-mail: vaniacmotta@gmail.com

3 Professora Mestra pela Universidade Federal do Rio de Janeiro (UFRJ). Doutoranda na mesma universidade. e-mail: carolina.andradep@gmail.com
} 
field of education. Considering the unbreakable organicity betweenn strcture and superstrcture and the particularities of brazilian social formation, we define two dimensions of this process: the capitalization of education (whose main aspects are mercantilizantion and merchandising) and the subsumption of education to empresariado. We point out implications for Brazilian education in view of the increase in precariousness and expropriation of the formative process, conditions necessary to guarantee adequate conditions for the reproduction of capital.

Keywords: Capitalization of education; Empresariamento of education; Subsumption of education to empresariado; Dependent capitalism.

\section{Introdução}

0 artigo versa sobre o empresariamento da educação, processo problematizado pelo Coletivo de Estudos em Marxismo e Educação, da Universidade Federal do Rio de Janeiro (COLEMARX/UFRJ), para designar o progressivo protagonismo assumido por frações empresariais na educação brasileira nos últimos trinta anos. Tal protagonismo robustece a trincheira de poder junto ao Estado ampliado por meio dos aparelhos privados de hegemonia, reunindo aliados e assumindo a aparência de "movimento social progressista", conquanto seus intelectuais ocupam cargos dirigentes junto ao Estado estrito - nos poderes executivo e legislativo e nas redes públicas municipais, estaduais e federais. Em última instância, esta forma de atuação visa garantir as condições adequadas à reprodução ampliada do capital.

Na primeira parte apresentamos o caminho de construção do conceito empresariamento da educação de novo tipo, indicando os referenciais teóricos que nos deram suporte e pesquisas com as quais dialogamos. Nas partes seguintes discutimos as duas dimensões que consideramos centrais para defini-lo: a capitalização da/na educação (que abarca a mercantilização e a mercadorização) e a subsunção da educação ao empresariado. Ressaltamos que, nesse processo, tais dimensões estão profundamente imbricadas e não ocorrem de forma apartada; a distinção é, pois, apenas teórica. 


\section{Pilares teóricos do Empresariamento da Educação de Novo Tipo}

A organicidade do empresariado brasileiro e a sua inserção no âmbito da educação, inclusive na formulação e implementação das políticas públicas, é um fenômeno passível de ser observado na história da educação com expressões variadas. Cientes da complexidade desse processo, consideramos necessário apresentar o arcabouço teórico que sustenta o entendimento de que o empresariamento da educação é uma das faces do projeto econômico e ético-político forjado e operado pela classe dominante. A despeito dos embates estabelecidos entre suas diferentes frações, entendemos que esta age como classe para si organicamente vinculada ao Estado, sobretudo quando diante de crises econômicas e políticas e do tensionamento de sua supremacia.

Diniz (2010) afirma que os empresários revelaram, ao longo do século XX, praticidade e alta capacidade de mobilização política em prol de seus interesses, apoiando distintos regimes políticos (ditaduras ou democracias). Bianchi (2001) revela o histórico e progressivo processo de organização do empresariado no Brasil desde os anos 1920 e os respectivos níveis de correlação de forças - inicialmente restrita ao âmbito econômico corporativo, chegando ao nível ético-político ${ }^{4}$ nos anos 1980, com a criação da entidade Pensamento Nacional das Bases Empresariais. No âmbito da educação, Miranda; Rodrigues (2017) apontam a criação do Serviço Nacional de Aprendizagem Industrial (SENAI) por meio de decretos estatais (Decretos no 4.048/42 e no 4.936/42) com o objetivo de formar o quadro de trabalhadores da indústria. E, mais recentemente, destaca-se o movimento Todos Pela Educação, criado em 2006 por um grupo de empresários que, junto com seus aliados nacionais e internacionais ${ }^{5}$, cumpre a função de manter e operar a supremacia burguesa.

\footnotetext{
4 As trincheiras de entidades empresariais que operam no âmbito ético-político ampliaram significativamente, a exemplo dos "think tanks nacionais (Instituto Millenium, Instituto Liberdade, Estudantes pela Liberdade, Fórum pela Liberdade, entre outros) e estrangeiros (Mont Pelèrin Society, Students for liberty, Friedrich Naumann, Cato Institute, John Templeton Foundation, Heritage Foundation..." (LEHER; VITTORIA; MOTTA, 2017, p. 17).

5 Tais como o Grupo Pão de Açúcar, Fundação Itaú-Social, Instituto Itaú Cultural, Fundação Bradesco, Instituto Gerdau, Fundação Roberto Marinho, Fundação Ayrton Senna, Fundação
} 
Os estudos do nosso coletivo têm apontado diferentes formas de protagonismo assumidas hoje pelo empresariado ${ }^{6}$, dadas as novas determinações cunhadas pela consolidação do bloco histórico neoliberal (CASTELO, 2011), pela complexificação da sociedade civil e pelo robustecimento das trincheiras formadas pelas organizações sociais patronais no âmbito ético-político. Neste, o empresariamento de novo tipo (FONTES, 2010) se expande e converte todas as atividades da vida social em meios de lucratividade. Este processo, no Brasil, guarda especificidades que, para o coletivo, devem ser analisadas à luz da dependência, entendendo que esta "não é a relação de uma economia nacional nativa com uma economia que a submete, mas sim uma relação básica que constitui e condiciona as próprias estruturas internas das regiões dominadas ou dependentes" (SANTOS, 1995, p. 15-16). Uma relação básica constituída na unidade dialética dependência-imperialismo, em uma "mesma unidade histórica que tornou possível o desenvolvimento de alguns e inexorável o atraso de outros" (BAMBIRRA, [1974] 2015, p. 44), sendo este "atraso", simultaneamente, consequência e condição do desenvolvimento das potências mundiais.

De modo geral, nossas análises têm demonstrado que o processo de empresariamento de novo tipo na educação combina e expressa, dialeticamente, o aprofundamento de movimentos históricos, estruturais e tendências do capital, as características particulares do bloco histórico neoliberal e as especificidades da formação econômico-social brasileira erigida sob a legalidade do capitalismo dependente. Isto é, esse empresariamento específico, de um lado, ilumina a tendência do capital de, ao desenvolver a dialética do seu devir, abranger e subjugar à sua lógica todas

\footnotetext{
Educar-DPaschoal, Banco ABN-Real, Instituto Ethos, entre outros, além de organismos internacionais que apoiam.

${ }^{6}$ Estamos utilizando empresariado para nos referirmos a um seleto grupo de empresários (banqueiros, industriais, agropecuaristas, financistas e respectivos executivos) que, dotados de uma determinada "capacidade técnica e dirigente", assumem posição de prestígio e, portanto, de confiança na relação social de produção capitalista. Com essa expressão, fundamentada na concepção de intelectual orgânico em Gramsci (2001), buscamos abarcar a lógica empresarial - sua capacidade técnica que penetra em todas as esferas da relação social por meio de vários mecanismos de controle - e sobretudo sua capacidade dirigente, de produção de vários tipos de consenso.
} 
as condições de reprodução social. De outro, deixa transparecer na educação a primazia do mercado, $\mathrm{o}$ ataque aos direitos e garantias sociais, a hegemonia da concepção econômica da educação, a fragilidade da democracia brasileira e o alinhamento da educação ao nexo da dependência e ao padrão de acumulação característico do bloco histórico neoliberal. No âmago dessa legalidade particular, o empresariado combina farsa e tragédia: apresenta-se como o grupo social que gera riqueza, trabalho e renda para a "nação" em meio a seu reverso - um capitalismo exacerbadamente perverso sustentado pela miséria da classe trabalhadora -, colocando-se como aquele que elevará moral e culturalmente a massa de trabalhadores, ao passo que expropria seus conhecimentos elementares e dirige o processo de apassivamento destas.

Tentando abarcar esse complexo conjunto, definimos como dimensões centrais do empresariamento a capitalização da educação (processo pelo qual a educação escolar vem operando como capital no sentido de funcionar valor e potencial mais-valor) e a subsunção da educação ao empresariado (processo pelo qual o empresariado brasileiro assumiu, em íntima relação com o Estado estrito e com o empresariado internacional, o protagonismo da formulação, aprovação e implementação das políticas públicas educacionais).

A despeito do discurso de resolução dos problemas que atravessam historicamente a educação brasileira, como os de acesso, aprendizagem e permanência, tal protagonismo empresarial tem sido acompanhado pela expropriação dos conteúdos escolares elementares no campo científico, tecnológico, filosófico, cultural e artístico, de modo a negar ao alunado brasileiro "os fundamentos das ciências que permitem aos jovens entender e dominar como funciona o mundo das coisas e a sociedade humana" (MOTTA; FRIGOTTO, 2017, p. 369); pelo aprofundamento do apartheid socioeducacional, cerceamento/expropriação do trabalho docente, desqualificação/ requalificação da formação docente, redução progressiva do processo de escolarização à simples transferência de competências e habilidades necessárias a um suposto mercado de trabalho que demanda 
maior "qualificação"7 e um tipo resiliente de trabalhador. Enfim, observamos que, em prol da elevação dos índices educacionais, aprofundam-se problemas

históricos e expandem-se as empresas de ensino a distância, de livros e materiais didáticos e think tanks internacionais sob o incentivo do Estado e sob o domínio do capital portador de juros que, "contraditoriamente, afastase da produção de mais-valor e a impulsiona, assim como promove novos e profundos processos de expropriação" (FONTES, 2010, p. 12).

Destacamos que o empresariamento da educação de novo tipo, para o nosso coletivo, não se confunde com a privatização do tipo clássico, em que há venda de patrimônio público para alguma empresa ou conjunto de investidores, que são tratados como "ativos". Atualmente, a tomada de controle sobre a educação por parte das empresas, seja no âmbito da formulação de políticas públicas, da administração direta da instituição ou via parceria público-privada, é suficiente para trazer à baila (i) a consolidação e expansão da educação enquanto nicho de mercado, (ii) a incorporação da educação à gama de mercadorias produzidas e consumidas na sociedade capitalista e (iii) a subsunção da educação à concepção e à lógica do empresariado e o repasse de verbas públicas para este grupo. Assim, embora o empresariamento não seja um fenômeno manifesto apenas no âmbito educacional, consideramos fundamental envidar esforços no sentido de compreender as especificidades que o protagonismo empresarial assume na educação escolar na sua atual forma, contribuindo para desmistificar o

\footnotetext{
${ }^{7}$ Qualificação entre aspas para sinalizar que o nosso coletivo problematiza a utilização deste termo para tratar da escolarização característica da atual sociedade capitalista brasileira. Compreendemos que, historicamente, a concepção econômica da educação - aquela que, ao estabelecer relação linear e causal entre educação e crescimento econômico, reduz a educação escolar à preparação da classe trabalhadora para o mercado de trabalho - é hegemônica e rege todas as ações das frações capitalistas no âmbito educacional. Neste sentido, concordamos com Bruno (2011) que a qualificação é um "estoque de competências"; uma estrutura de elementos mutáveis historicamente e hierarquizáveis de diferentes formas, mas sempre determinados pelas especificidades das relações de produção e dos processos de trabalho vigentes e predominantes. A nosso ver, todavia, perante às novas características do mundo do trabalho sob a égide neoliberal (como a atomização das relações de trabalho, o protagonismo da informalidade, da flexibilidade, da alta rotatividade, e outros) a estrutura dessa qualificação foi alterada de tal modo que sequer pode significar um "estoque de competências" ou "estoque de capital humano".
} 
discurso burguês que naturaliza as relações de opressão e exploração enredadas na sociedade burguesa.

Nas linhas que se seguem, apresentaremos as duas dimensões centrais e imbricadas do empresariamento da educação de novo tipo que mencionamos: a capitalização da/na educação (que abarca a mercantilização e a mercadorização) e a subsunção da educação ao empresariado.

\section{O devir do capital e a reprodução social: a capitalização da/na educação brasileira}

Ao nos referirmos à capitalização da educação estamos tratando do processo pelo qual a educação opera como capital. Neste âmbito, conferimos a devida atenção ao processo de mercantilização, pelo qual imputa-se à educação valores de uso e de troca, reifica-se o processo educativo e transforma-se a educação em meio de produção de

certificados. Historicamente, tal mercadoria é consumida permanentemente por parte da classe trabalhadora, mormente calcada na crença em uma suposta relação linear entre educação e ascensão social, e por parte da classe burguesa, que a consome enquanto compósita da mercadoria força de trabalho, da qual extrai-se mais-valor. Por sua vez, a mercadorização é concebida por nós como o processo pelo qual o âmbito educacional é transformado em nicho de mercado que, em acelerada expansão, ratifica, também, a necessidade constante da produção capitalista de criar novos mercados (MARX, 2017).

Descrito detalhadamente por Marx em 1857-1858, a capitalização é um processo de fundamental importância para a apreensão do movimento pelo qual o capital abrange todas as esferas da existência humana. Destacamos que a capitalização diz respeito à gênese, existência e expansão do capital, isto é, ao processo pelo qual o capital passa a existir e criar, concomitantemente, as condições para continuar existindo e se expandindo (MARX, 2011). Noutros termos, o próprio capital realiza os momentos necessários à sua autoformação e contém as condições para sua realização. Três aspectos constituem o capital enquanto relação social: (i) a conservação 
de seu valor pela troca com o trabalho vivo; (ii) a criação de um valor excedente via exploração da força de trabalho e (iii) a desvalorização como parte da sua valorização.

A capitalização inclui diversos "subprocessos". Para expor sinteticamente o processo de capitalização da e na educação, dois deles nos parecem centrais: a mercantilização e a mercadorização. Estes processos ocorrem "na educação" quando os meios e objetos desse âmbito são subsumidos à lógica da mercadoria e/ou lançados no mercado como mercadorias singulares, a exemplo dos livros didáticos, apostilas, tecnologias educacionais, entre outras; são "da educação" quando englobam a educação enquanto processo educacional voltado para a capacitação da força de trabalho, subsumindo-a à forma-mercadoria e lançando-a no mercado como conjunto de mercadorias potenciais e/ou como mercadoria a ser necessariamente consumida pela classe trabalhadora ${ }^{8}$.

Como dissertou Marx (2013, p. 113), a mercadoria é algo que "por meio de suas propriedades, satisfaz necessidades humanas de um tipo qualquer", não importando a natureza dessas necessidades nem de que modo a mercadoria a satisfaz. Nestes termos, a utilidade da mercadoria faz dela valor de uso, que independe das propriedades do seu corpo. No Modo de Produção Capitalista (MPC), no entanto, essa mercadoria é também o suporte do valor de troca, que não é determinado pelo valor de uso; ao contrário, é somente pela troca que a mercadoria pode ser realizada. No MPC, portanto, a satisfação das necessidades humanas, sejam do estômago ou da fantasia, perpassa a troca.

A teoria do valor-trabalho de Marx permite compreender não só que entre valor e tempo de trabalho despendido há uma relação íntima e direta,

\footnotetext{
8 Decerto, a força de trabalho é mercadoria construída e reconstruída historicamente, também de acordo com as necessidades candentes do Modo de Produção Capitalista (MPC). Sendo assim, a nossa descrição dos processos mencionados tem em sua base o entendimento (i) de que a educação é, historicamente, um dos elementos que compõem diretamente a produção social da força de trabalho, sendo portanto seu elemento constitutivo, e (ii) de que esses processos, embora tendências do MPC, nem sempre atravessaram a educação. Neste sentido, compreendemos que estas tendências são aceleradas e robustecidas em tempos de empresariamento da educação de novo tipo ao qual, não ao acaso, a postulação da necessidade de formação de um "novo trabalhador" é evento sincrônico.
} 
mas também que é precisamente na exploração da força de trabalho que reside a origem de todo e qualquer valor novo que permita a ampliação da reprodução do capital. Outrossim, que a produção desse valor novo é primeiro e último objetivo da produção capitalista, que por sua vez "não é apenas produção de mercadoria, mas essencialmente produção de maisvalor. 0 trabalhador produz não para si, mas para o capital. Não basta, por isso, que ele produza em geral. Ele tem de produzir mais-valor" (MARX, 2013, p. 706). Sendo assim, é com o objetivo de produzir mais-valor que o capitalista despende, no âmbito da produção, capital na forma constante (para empregar máquinas e matérias primas) e na forma variável (para empregar a força de trabalho - a única capaz de produzir mais-valor).

Com base nessas compreensões, Bruno (2011) disserta sobre como os valores de uso e de troca das mercadorias empregadas no âmbito da produção capitalista podem assumir uma relação contraditória, a depender da perspectiva de classe. Explica a autora que a força de trabalho é valor de uso para o capitalista, já que ele a explora para produzir mais-valor e a usa para transferir o trabalho morto cristalizado nos seus meios de produção para novas mercadorias. Por isso mesmo, ao capitalista interessa reduzir ao mínimo possível o valor de troca dessa mercadoria. Se observamos a questão sob a ótica do trabalhador, entretanto, embora a sua força de trabalho, apartada dos meios de produção, não tenha valor de uso imediato à si mesmo para produzir nem mesmo sua existência, a sua própria força de trabalho lhe serve como valor de uso quando ele se organiza para lutar contra a exploração.

Justamente no que tange à efetivação do valor de uso da mercadoria força de trabalho compreendemos que a educação escolar interessa historicamente à classe burguesa, à medida que esta pode potencializar a produção de mais-valor. Nesse sentido, não ao acaso, em tempos de empresariamento, ela é reduzida cada vez mais ao repasse de competências e habilidades estritamente necessárias ao mundo do trabalho, flexível e precarizado. Outrossim, não é de surpreender que, mesmo se concebida como direito social, a educação seja subsumida à forma-mercadoria e alvo de 
grandes ações do capital, bem como que assuma valores de uso e de troca contraditórios ${ }^{9}$. Embora a ideologia burguesa esqueça-se (convenientemente) de todos os fatores que incidem sobre o valor da força de trabalho, afirmando que a educação deve ser permanentemente consumida porque (supostamente) reverbera em melhores salários e condições de trabalho e de vida, sabemos que a escolaridade não necessariamente assume um valor de uso para o trabalhador neste sentido vide o enorme contingente de, sobretudo jovens, graduados, mestres e doutores desempregados (IBGE, 2018). Mais que isso, podemos mencionar que, na contemporaneidade, o trabalhador não pode se relacionar com a escolarização como valor de uso sequer para ler e compreender o mundo, já que essa última não lhe oferece ferramentas para tal. Assim, a capacitação, longe de reduzir a alienação da força de trabalho e de permitir que o trabalhador relacione-se com ela como valor de uso, parece potencializar o valor de uso da força de trabalho para o capitalista.

Vale lembrar, todavia, que os elementos que historicamente compõem a educação da força de trabalho não são apenas físicos ou cognitivos, mas também morais, éticas, emocionais e psíquicas, necessários às formas de organização do trabalho e da vida social.

Neste sentido, com Bruno (2011) compreendemos que, historicamente, qualificar a classe trabalhadora significa conferir à este qualquer tipo de capacidade, desde que seja passível de ser utilizada pelo capitalista na produção de valor e de mais-valor. Por certo, as formas pelas quais o capitalista desfruta deste valor de uso depende de inúmeros fatores, tais como a cadeia produtiva local e a formação econômico-social dos países e, portanto, o tipo e o grau de qualificação da classe trabalhadora mais eficiente ao capitalista, ou seja, que melhor potencialize o valor de uso da mercadoria força de trabalho.

\footnotetext{
${ }^{9}$ Um adendo: não estamos afirmando, em hipótese alguma, que todas as desventuras e devaneios que parecem assombrar os sistemas educacionais tenham como causa ou derivem exclusivamente de problemas de base econômica. Isto será, inclusive, abordado mais adiante. Por ora, nosso objetivo é apenas destacar um dos aspectos que nos parece ainda permanecer enuviado no âmbito da compreensão da relação dialética entre educação, força de trabalho e capital.
} 
Que a força de trabalho humana é imediatamente útil para o capitalista não deve, porém, encobrir o fato de que a ele interessa a redução do valor de troca dessa mercadoria, tendo em vista reduzir o dispêndio de capital variável. Nestes termos, se o valor da mercadoria é diretamente proporcional ao tempo de trabalho despendido na sua produção, e se assumirmos a capacitação como um elemento compósito da mercadoria da força de trabalho, não parece equivocado afirmar que interessa ao capitalista a redução do tempo de trabalho socialmente necessário à capacitação da força de trabalho, inclusive via aumento da produtividade do trabalho envolvido nos processos de capacitação ${ }^{10}$. Em síntese, apreendemos que ao capitalista interessa que a capacitação da força de trabalho confira as competências necessárias à produção de mais-valor no menor tempo possível, de forma a minimizar o valor de troca da força de trabalho e maximizar a realização do seu valor de uso.

Ratificamos, no entanto, que o interesse do capital na produção da mercadoria força de trabalho e no rebaixamento de seu valor é elemento característico e histórico da sociedade burguesa. De forma semelhante, entendemos que é tendência do capital, conforme se desenvolve, penetrar em todas as esferas sociais e incorporar sua lógica em todas as formas de existência e reprodução social, subjugando-as à lógica da mercadoria. Estamos concebendo, então, a mercantilização da educação como processo pelo qual a educação escolar é transformada unicamente em elemento constitutivo da mercadoria força de trabalho. Desse modo, subsumida à forma-mercadoria, o seu primeiro possuidor (o trabalhador) não se relaciona imediatamente com esta capacitação como valor de uso, mas apenas como valor de troca. Neste processo, então, essa educação passa a ter em si um valor incorporado, de forma que este meio de produção e reprodução social da existência, como valor de uso, serve de suporte para o valor de troca e torna-

\footnotetext{
${ }^{10}$ Neste processo podemos indicar as reformas curriculares que reduzem a carga-horária ou eliminam disciplinas não imediatamente úteis ao processo de valorização do valor, como também a defesa de ofertar ensino a distância como complemento curricular ou como forma de capacitação da força de trabalho, o que economiza enormemente e principalmente as despesas na forma de capital constante.
} 
se absolutamente alienável. Outrossim, nesse processo, apaga-se paulatinamente o seu caráter humano, processual e social, transformando a educação em uma coisa a ser consumida com vistas à troca.

Assumimos a mercantilização da educação como uma das faces características do empresariamento da educação com traços de "novo tipo", à medida que o protagonismo do empresariado na educação, ao vincular cada vez mais diretamente capacitação e trabalho, exacerba essa tendência histórica da sociedade de classes, qual seja, a subsunção da educação à forma e lógica da mercadoria. Diante da atual e forte concentração capitalimperialista e das renovadas modalidades de exploração, bem como da ampliação da superpopulação relativa ${ }^{11}$, é necessidade deste empresariado, para concretização do seu projeto econômico e ético-político, não só o controle sobre o conteúdo da capacitação no que concerne ao exercício do trabalho, mas também sobre os mecanismos de apassivamento da classe trabalhadora.

A subsunção da educação à lógica da lucratividade e à formamercadoria fora acompanhada, dialeticamente, pela peremptória transformação da educação em nicho de mercado, no qual tanto a educação escolar em si quanto suas ferramentas subjacentes (materiais didáticos, prédios, avaliações, sistemas de ensino e outros) são trocadas pela forma fenomênica (equivalente universal) do valor. Nesse sentido, compreendemos que, de um lado, a constituição da educação enquanto nicho de mercado corrobora a tendência do capital de subsumir as formas de reprodução social às suas determinações fundamentais, bem como de imputar a satisfação das necessidades humanas via troca no mercado. De outro, entendemos que, de forma geral, a expansão dos nichos de mercado, frequentemente acompanhada por medidas como acordos de livre comércio e privatização clássica de empresas estatais, vem sendo concretizada e acelerada em

\footnotetext{
${ }^{11}$ Superpopulação Relativa ou o Exército Industrial de Reserva (EIR) refere-se a parte do proletariado que não é inserida no mercado de trabalho, pois tal parcela, essencialmente, é condenada a uma "ociosidade forçada em virtude do trabalho excessivo de outra parte" da classe trabalhadora e é funcional ao Modo de Produção Capitalista (MPC) na medida em que força de sobremaneira a redução do valor da mercadoria força de trabalho, já que mantém a sua oferta patamares superiores ao demandado pelo Capital (MARX, 2017, p.716).
} 
conjunturas específicas, como movimento de resposta às crises capitalistas seja como movimento contratendencial à queda na taxa de lucro, como meio de aliviar as pressões da sobreacumulação e/ou de proporcionar o escoamento das mercadorias que, ao saturarem o mercado e a capacidade de consumo da população, não podem concluir seu salto mortal e ter seus valores realizados.

Não é nosso objetivo, entretanto, afirmar que somente na esfera econômica residem as origens do empresariamento da educação, nem em suas formas históricas, nem em suas formas hodiernas. Primeiramente, é preciso salientar que também questões ético-políticas, além das econômicas, levam a burguesia a se organizar em aparelhos privados de hegemonia para disputar, sistemática e historicamente, um projeto político pedagógico hegemônico (à exemplo dos empresários industriais que, organizados na Confederação Nacional da Indústria desde 1930, disputam uma pedagogia industrial). Em segundo, vale lembrar que a natureza do conteúdo e da forma da educação escolar guarda íntima relação com o destino do trabalho, que na sociedade capitalista é necessariamente alienado. Isto não significa, contudo, que a relação entre educação e trabalho seja meramente de preparação física e/ou cognitiva; estando subjugada ao capital - uma incontrolável e incorrigível totalidade reguladora sistêmica (MESZÁROS, 2005) -, a educação deve, além de fornecer à maquinaria o pessoal devidamente treinado, gerar e transmitir um conjunto de valores que legitima os interesses dominantes, ou seja, que induz a perpetuação e aceitação passiva do sistema que explora o trabalho como mercadoria, bem como a interiorização de uma concepção de mundo coerente com essa sociedade (SADER, 2005). Sendo assim, sob a égide do capitalismo, a classe dominante impõe uma educação para o trabalho alienante e mesmo que esta possibilite acúmulo de conhecimento, este não deve ser traduzido em compreensão de mundo que promova a desalienação. Nesse sentido a educação no capitalismo apresenta, necessariamente, uma dimensão apassivadora.

Trocando em miúdos, no capitalismo, não cabe à educação escolar apenas tornar o indivíduo apto à produção de mais-valor; cabe-lhe, também, 
fazer com essa produção seja consentida. Nesse âmago, se a educação escolar é espaço de construção e exercício

de hegemonia é, também, espaço de contra-hegemonia, de modo que não por acaso, historicamente, classes e frações de classe disputam conteúdo e forma da educação escolar, ainda que sob o mote de reformas.

Compreendemos com Gramsci (2007) que o decorrer do desenvolvimento capitalista foi acompanhado da complexificação da luta de classes, que não mais se reduz ao confronto direto. A elevação das superestruturas político-ideológicas sobre determinada estrutura econômica, fortificadas pela multiplicação dos aparelhos privados de hegemonia à serviço da classe burguesa na sociedade civil, fortaleceu de sobremaneira a estrutura capitalista e a sua forma de Estado correspondente, à medida que inseriu uma dimensão hegemônica à luta de classes. A luta de classes não mais se reduz à luta pelos aparelhos de dominação, isto é, à luta para tornar-se dominante; é também, a partir de então, luta para tornar-se dirigente. Nesse sentido, uma luta de hegemonias se trava no seio da sociedade civil - uma estrutura entrincheirada, complexa e muito "resistente às 'irrupções' catastróficas do elemento econômico imediato (crises, depressões, etc)" (GRAMSCI, 2007, p. 73). Historicamente, a escola é decerto um dos aparelhos privados/estatais de hegemonia que, embora permanentemente disputado, funciona também como instrumento de cimentação do conformismo das massas e de construção do consenso ativo e passivo, sempre respaldadas por estruturas coercitivas.

Enfim, a nosso ver, o fato de que "métodos de trabalho são indissociáveis de um determinado modo de viver, de pensar e de sentir a vida; não é possível obter êxito num campo sem obter resultados tangíveis no outro" (GRAMSCI, 2007b, p. 266), bem como o de que não basta que capital e trabalho apareçam em polos opostos; é preciso desenvolver "uma classe de trabalhadores que, por educação, tradição e hábito, reconhece as exigências desse modo de produção como leis naturais e evidentes por si mesmas" (MARX, 2013, p. 982), corrobora a dialética existente entre trabalho e 
sociabilidade, além de nos ajudar a pensar o lugar da educação nessa sociedade.

De nossa ótica, o aprofundamento da mercantilização e da mercadorização da educação são indissociáveis da agudização de sua dimensão apassivadora, alienante e do funcionamento da escola como aparelho de hegemonia majoritariamente à serviço da classe burguesa, a despeito da assim chamada "rebeldia" de profissionais da educação e alunos. Isso porque a subjugação da educação à lógica da lucratividade, de um lado, precisa ser consentida pela classe trabalhadora e cimentada socialmente; de outro, tende a expropriar, progressivamente, todo conteúdo que não for requerido pelo trabalho alienado e pela sociabilidade burguesa, estreitando assim os caminhos pelos quais a classe trabalhadora tem a possibilidade de forjar e operar uma educação escolar minimamente contra a corrente.

3. Conteúdo e forma da educação escolar em tempos de aprofundamento da irracionalidade social do capital: a subsunção da educação ao empresariado

A subsunção da educação ao empresariado parece ser a forma mais eficiente que o capital encontrou para maximizar o seu controle sobre o processo educativo, determinando seu conteúdo e forma em fina sintonia com os seus interesses. Nessa tomada da dianteira, as ações do empresariado aumentam a precarização e o esvaziamento do processo educativo, a partir da sua subsunção à lógica empresarial e ao ethos gerencialista de controle. Tais ações irão reverberar no tempo e no conteúdo da (con)formação da classe trabalhadora (MOTTA, 2012), bem como na discriminação dos valores relativos às mercadorias e na dinâmica do mercado educacional.

Inúmeros trabalhos discorrem sobre a crise orgânica dos anos 1970 que levou à transição do bloco histórico fordista-keynesiano para o bloco histórico neoliberal (CASTELO, 2011) e sobre os seus desdobramentos particulares no Brasil. Não é nosso objetivo aqui retomar os pormenores da ascensão e consolidação do neoliberalismo no mundo e especificamente no Brasil, mas apresentar resumidamente a nossa leitura sobre a forma com que esse conjunto de medidas econômicas, políticas e sociais reunidas na 
doutrina neoliberal impactou a educação brasileira, no que tange tanto aos seus aspectos relacionados à estrutura quanto a superestrutura desse novo bloco histórico.

Alguns aspectos que sustentam a nossa leitura precisam ser destacados. Um deles é que, globalmente, a despeito dos esforços da burguesia em torno da ampliação da extração de mais-valor (vide a reestruturação produtiva, a degradação dos salários, a flexibilização do regime trabalhista e outros), as taxas de lucro não voltam a atingir os elevados patamares anteriores à recessão de 1973-1975. De acordo com Alves (2017, s./p.), a recuperação da taxa de lucro foi calcada em um complexo de contratendências que aprofundaram a claudicância estrutural do capital e que continha em si a semente da crise financeira de 2008 , que mergulhou o capitalismo global na sua terceira grande depressão ${ }^{12}$.

O segundo refere-se ao fato inquestionável de que a doutrina neoliberal globalizou e aprofundou de sobremaneira as expressões da "questão social", de modo que a realidade tratou de demonstrar a fragilidade ideológica do neoliberalismo, com destaque para a apologia às desigualdades. Mesmo com a onda de subversivismo das classes subalternas na década de 1990, que obrigou o Estado neoliberal a conferir uma face mais humana ao capital sob auspício de uma sociedade harmoniosa (MOTTA, 2012), a metamorfose que sofrera o mundo do trabalho foi acompanhada por uma aparente irreversível precarização de todas as condições de existência humana. Diante dessa conjuntura específica, vale relembrar que a educação foi clamada, sobretudo por organismos internacionais (BIRD, BID, ONU e suas unidades) a acobertar o antagonismo de classe com a possibilidade de uma relação harmônica entre mercado, Estado e sociedade civil, em prol "do

\footnotetext{
12 Concordamos com Alves (2017, s./p.) que uma depressão na economia capitalista global "não significa que ela não cresça, mas sim, que as taxas de recuperação da atividade são tão frágeis, comparadas com aquelas do período anterior à Grande Recessão, que as economias podem desacelerar e voltar a cair numa recessão". É o que tem se verificado desde 2008 nas economias do capitalismo central. E compreendemos a recessão da economia brasileira, iniciada em 2015, como parte desta depressão.
} 
acesso dos mais pobres aos benefícios econômicos e bens socioemocionais já disponíveis na sociedade" (MOTTA, 2012, p. 195).

Embora o neoliberalismo tenha entrado no Brasil pelas mãos de Collor, a contrarreforma do Estado iniciada em 1995, no governo de Cardoso, é emblemática por coroar o alinhamento do Brasil às essências do bloco histórico neoliberal e por criar condições favoráveis à expansão do grande capital-imperialismo. Dentre seus princípios básicos que mais atingiram a educação estão a concepção de "público não estatal" e a compreensão de "publicização" como "um sistema de parceria entre Estado e sociedade para seu financiamento e controle" (BRASIL, 1995, p. 13), a partir das quais desdobrou a regulamentação de entidades sociais privadas de interesse público e das parcerias público-privadas. Estes conduziram o deslocamento da educação como direito social e universal para "serviço público não ${ }^{13}$ estatal", colocando em xeque a garantia constitucional do direito à educação. 0 cimento ideológico desta formulação é o envolvimento dos cidadãos nos assuntos públicos, atribuindo caráter consensual ativo, o que também insere um processo educativo do consenso espontâneo, qual seja a persuasão e o apassivamento da classe trabalhadora sob as novas condições de extração de mais-valor sem, no entanto, abrandar a truculência repressiva (FONTES, 2010).

Em suma, pode-se afirmar que a contrarreforma do Estado proporcionou as condições legais para a expansão do empresariamento de novo tipo na sociedade civil, inclusive na educação. Ainda em 1995, os paísesmembros da Organização Mundial do Comércio (OMC) assinaram o Acordo Geral sobre Comércio de Serviços (GATS), cujo objetivo era a liberalização progressiva dos serviços em dez anos, incluindo a educação ${ }^{13}$. À época, várias organizações aliadas ao setor empresarial já atuavam em parceria com a

\footnotetext{
13 Diante das dificuldades para concluir as negociações, o GATS não foi concluído, mas substituído por acordos bilaterais. Em 2012 teve início uma negociação sigilosa para um novo tratado denominado TiSA (Acordo sobre o Comércio de Serviço) que fez frente à entrada incisiva da OCDE no controle da educação, por meio do Programa Internacional de Avaliação de Alunos (PISA), mecanismo que vem guiando as avaliações em larga escala de vários países e formulando, subliminarmente, o conceito de qualidade na educação.
} 
escola pública, a exemplo do Centro de Estudos e Pesquisas em Educação, Cultura e Ação Comunitária (CENPEC) e da Fundação Ayrton Senna. Em 1999, o "Pacto Global" anunciado no Fórum Econômico Mundial conclamou empresários a adotar políticas de responsabilidade social com vistas à harmonização do sistema; ainda em 1999, o bloco no poder assegurou o interesse privado na educação pública aprovando a lei 9.790/1999, que criou as "Organizações da Sociedade Civil de Interesse Público (OSCIP)", com liberdade para atuar na "promoção gratuita da educação, observando-se a forma complementar de participação das organizações de que se trata esta lei" (BRASIL, 1999).

Já em 2001, frações empresariais locais criaram o Movimento Brasil Competitivo (MBC), presidido pelo empresário Jorge Gerdau Johannpeter, em ${ }^{14}$ parceria com o Banco Mundial e a "ressuscitada" Agência dos Estados Unidos para o Desenvolvimento Internacional (USAID), copatrocinado pela Merck Sharp \& Dohme, pela Petrobras, e outras grandes empresas" (MOTTA, 2012, p.125). O MBC passou a difundir premissas para "solucionar a questão de um setor público inflado, assim como o problema da burocracia, solapadora de ambiente de negócios" (MOTTA, 2012, p. 143), em direção ao maior diálogo entre governo e setor privado. Do MBC nasce, cinco anos depois, o Movimento Todos Pela Educação (TPE), que tomou a dianteira da formulação, consolidação e implementação das políticas educacionais do governo Lula e que conferiu uma organicidade sem precedentes às ideias do grupo empresarial no âmbito da educação.

[...] estas forças lograram firmar um eixo discursivo que irá orientar as ações do capital nos anos seguintes: a educação fundamental foi universalizada, mas carece de qualidade; o Estado e os professores fracassaram na reversão do quadro de repetência, de evasão e de baixo desempenho escolar, então, é legítima a participação ativa da sociedade civil, leia-se, das organizações vinculadas ao capital, na condução dos assuntos educacionais, ainda que em confronto com professores avessos às tais "reformas" (MOTTA; LEHER, 2017, p. 245).

A nosso ver, a subsunção da educação ao empresariado é um processo que entra em curso no seio da "reforma" do Estado brasileiro e do bloco 
histórico neoliberal, apresentando características peculiares que foram e continuam sendo exacerbadas com o decorrer do tempo. Sem adentrar às especificidades de cada governo, compreendemos que, no octanato de Lula da Silva (2003-2010) e também no governo Dilma Rousseff (2010-2016), mantiveram-se a promoção de reformas pró-mercado, exorbitantes taxas de juros, estrutura tributária regressiva ineficiente e a submissão ativa e consentida da política econômica ao capital rentista nacional e internacional, além dos movimentos de desregulamentação e privatização e da recorrência às políticas econômicas austeras sempre que necessário. Independentemente das nuances conjunturais dos últimos trinta anos, a capacidade técnica e dirigente do empresariado no âmbito da educação, isto é, a atuação sincronicamente empresarial e intelectual de seus integrantes, orgânica e sistemática em termos econômicos e ético-políticos, estruturais e superestruturais, com consentimento e aporte do Estado estrito, é uma tônica inquestionável.

Em síntese, no seio dessa nova estrutura marcada por menores taxas de lucro, pela precarização do trabalho e pela agudização da "questão social", bem como por um novo padrão de acumulação que demanda um grande volume de trabalho simples (LEHER, 2010), a abertura de portas para a atuação empresarial no âmbito da educação vem reverberando i) no aprofundamento da mercantilização da educação, que cada vez mais limitase a transferir competências (e não conhecimentos) mínimas e simples, que devem ser manejadas no exercício do trabalho simples; ii) no aprofundamento da sua dimensão apassivadora na medida em que a precarização do mundo do trabalho e o próprio aprofundamento da mercantilização vê $\mathrm{m}$ aniquilando possíveis formas desalienantes de educação, inclusive porque vêm expropriando toda forma de conhecimento em nome do desenvolvimento das competências; iii) no surgimento de novas formas de mercadorização da educação, que englobam a gestão de escolas públicas para o setor privado, a venda de sistemas completos de ensino para escolas públicas, a constituição de grandes empresas de capital aberto e capital de risco especificamente voltadas para a realização de negócios na 
educação, entre outros; iv) na subjugação da educação escolar à lógica do funcionamento empresarial e ao ethos gerencialista do controle.

\section{Considerações finais}

Há cerca de trinta anos, exponencialmente e sob o comando do empresariado organizado em aparelhos privados de hegemonia, combina-se transformação da renda social em capital, impulso à lucratividade, preparação para o exercício do trabalho e a conformação de uma determinada forma de consciência fortificada pela ideologia neoliberal. Como viemos observando, essa combinação vem tendo implicações profundas não só nos aspectos internos à educação brasileira (currículo, avaliações, docente e outros), mas em todas as esferas a ela relacionadas.

Não foi objetivo deste texto apresentar e discutir concretamente essas implicações, que podem ser encontradas em vários trabalhos do nosso coletivo (GAWRYSZEWSKI, 2018; ANDRADE; GAWRYSZEWSKI, 2018; ARGOLLO; MOTTA, 2015). Com esse trabalho objetivamos chamar atenção, primeiramente, para os aspectos estruturais e conjunturais que, juntos, endossam o empresariamento da educação de novo tipo e aprofundam a precarização e expropriação dos processos formativos mais complexos; segundo, para o fato de que a esfera educacional não se faz exceção ao ponto de vista da totalidade, tampouco da dialética estrutura-superestrutura. Por isso, pensar os problemas atuais da educação brasileira e lutar pela sua (certamente) possível transformação exige não só estar nas trincheiras da luta de hegemonias travada na sociedade civil, mas fazer frente aos aspectos da estrutura econômica que conformam um padrão de acumulação que sobrevive, independentemente do tempo histórico, da exploração e expropriação humana.

Essas afirmações decerto continuam a ser válidas diante da conjuntura de ascensão da atual aliança ultraliberal-ultraconservadora que compõe o bloco no poder. Conforme nos diz Iasi (2019), a chave analítica do tempo presente é o "fetichismo da mercadoria e os interesses de classe que daí derivam". Nesse sentido, sobretudo no âmbito da educação, é preciso fazer 
frente não só à superestrutura político-ideológica erigida por tal aliança e às resistências que essa nos exige, mas também aos aspectos concretos da estrutura econômica que tornaram necessária essa forma burlesca e obscurantista de Estado capitalista.

\section{Referências}

ALVES, G. A longa depressão do século 21 e a era da barbárie social - I. Disponível em: https://blogdaboitempo.com.br/2017/01/26/a-longadepressao-doseculo-21-e-a-era-da-barbarie-social-i/>, acesso em 04 jan 2019.

ANDRADE, M.C.; GAWRYSZEWSKI, B. Desventuras da educação brasileira e as 'reformas' atuais: educar para a produtividade do trabalho. EccoS Revista Científica, São Paulo, n. 47, p. 105-125. set/dez. 2018.

ARGOLLO, J.; MOTTA, V. Arranjos de desenvolvimento da educação: regime de colaboração de 'novo' tipo como estratégia do capital para ressignificar a educação pública como direito. Universidade e sociedade, $n^{\circ} 56$, p. 44 , agosto-2015.

BAMBIRRA, V. 0 capitalismo dependente latino-americano. Insular, 2015.

BIANCHI, A. Hegemonia Em Construção - a Trajetória do PNBE. Ed: Xamã, São Paulo, 2001.

BRASIL. Plano diretor da Reforma do Estado. DF: 1995.

BRUNO, L. Educação e desenvolvimento econômico no Brasil. Revista Brasileira de Educação, v. 16, n. 48, set.-dez. 2011.

CASTELO, R. O Social-Liberalismo: uma ideologia neoliberal para a "questão social" no século XXI. Tese (Doutorado em Serviço Social) - Escola de Serviço Social, Universidade Federal do Rio de Janeiro, 2011.

DINIZ, E. Empresariado industrial, representação de interesses e ação política: trajetória histórica e novas configurações. Revista Política e Sociedade, Volume 9, № 17, outubro de 2010.

FERNANDES, F. Sociedade de classes e subdesenvolvimento. Rio de Janeiro: Zahar, 1981.

FERNANDES, F. A revolução burguesa no Brasil. Rio de Janeiro: Zahar, 1975. 
FONTES, V. O Brasil e o capital imperialismo: teoria e história. Rio de Janeiro: EPSJV/Editora UFRJ, 2010.

GAWRYSZEWSKI, B. Crises capitalistas e conjuntura de contrarreformas: qual o lugar do ensino médio? Revista Pedagógica, Chapecó, v 19, n. 42, p. 83-106, set./ dez. 2018.

GAWRYSZEWSKI, B.; MOTTA, V.; PUTZKE, C. A agenda privada-mercantil educacional: a gestão privada de escolas públicas da educação básica. Anais Marx e o Marxismo 2017: de 0 Capital à Revolução de Outubro (18671917). Universidade Federal Fluminense, 21 a 25 ago. 2017.

GRAMSCI, A. Cadernos do Cárcere, volume 3. Rio de Janeiro: Civilização Brasileira, 2007.

GRAMSCI, A. Cadernos do Cárcere, volume 4. Rio de Janeiro: Civilização Brasileira, 2007b.

IASI, M. 0 fetichismo e as formas políticas: o Estado burguês na forma burlesca. Disponível em: < https://blogdaboitempo.com.br/2019/02/14/o-fetichismo-e-as-formaspoliticas-o-estado-burgues-na-forma-burlesca/>, acesso em 04 fev 2019.

LEHER, R. A educação no governo Lula da Silva: a ruptura que não aconteceu. In: Os anos Lula: contribuições para um balanço crítico 2003 2010, p.369-411. Rio de Janeiro: Garamond, 2010.

LEHER, R.; VITTORIA, P.; MOTTA, V. Educação e mercantilização em meio à tormenta político-econômica do Brasil. Germinal: Marxismo e Educação em Debate, Salvador, v. 9, n. 1, p.14-24, 2017.

MARX, K. 0 capital: crítica da economia política, livro I. São Paulo: Boitempo, 2013.

MARX, K. 0 capital: crítica da economia política, livro III. São Paulo: Boitempo, 2017.

MARX, K. Grundrisse. São Paulo: Boitempo, 2011.

MESZÁROS, I. Educação para além do capital. São Paulo: Boitempo, 2005.

MIRANDA, K.; RODRIGUES, J. Trabalho e Educação: perfil de formação da classe trabalhadora em um país dependente como o Brasil. In: Educação e Serviço Social: Subsídios para uma análise crítica. 1a ed. - Rio de Janeiro: Lumen Juris, 2017. 
MOTTA, V.; FRIGOTTO, G. Por que a urgência da reforma do ensino médio? Medida Provisória no 746/2016 (Lei no 13.415/2017). Educação e Sociedade, Campinas, v. 38, nํ. 139, p.355-372, abr./jun. 2017.

MOTTA, V.; LEHER, R. Trabalho docente no contexto do retrocesso do retrocesso. RTPS - Rev. Trabalho, Política e Sociedade, Vol. II, no 03, p. 243-258, jul-dez/2017.

MOTTA, V. Ideologia do capital social: atribuindo uma face mais humana ao capital. Rio de janeiro: Eduerj, 2012.

SADER, E. Prefácio. In: Mèszáros, I. Educação para além do capital. São Paulo: Boitempo, 2005.

SANTOS, T. Evolução histórica do Brasil: da colônia à crise da Nova República. Vozes: 1995. 